\title{
Correction to: Oral propranolol in prevention of severe retinopathy of prematurity: a systematic review and meta-analysis
}

\author{
A. Stritzke $\mathbb{1}^{1,2,3} \cdot$ N. Kabra ${ }^{4} \cdot$ S. Kaur ${ }^{5} \cdot$ H. L. Robertson ${ }^{6} \cdot$ A. Lodha ${ }^{1,2,7}$
}

Published online: 29 October 2019

(C) The Author(s), under exclusive licence to Springer Nature America, Inc. 2019

\section{Correction to: Journal of Perinatology}

https://doi.org/10.1038/s41372-019-0503-x

published online 30 September 2019
Since online publication of this article, the authors noticed that there is an error in affiliation 3. The correct affiliation details are provided below.

3. Libin Cardiovascular Institute of Alberta, University of Calgary, AB, Canada

A. Stritzke

Amelie.Stritzke@albertahealthservices.ca

1 Department of Pediatrics, Cumming School of Medicine, University of Calgary, Calgary, AB, Canada

2 Alberta Children's Hospital Research Institute, University of Calgary, Calgary, AB, Canada

3 Libin Cardiovascular Institute of Alberta, University of Calgary, Calgary, AB, Canada

4 Department of Neonatology, Surya Hospitals, Mumbai, Maharashtra, India

5 Department of Pediatrics, McMaster University, Hamilton, ON, Canada

6 Liaison Librarian, Clinical Medicine, Health Sciences Library, University of Calgary, Calgary, AB, Canada

7 Department of Community Health Sciences, University of Calgary, Calgary, AB, Canada 